\title{
Efficacy of vildagliptin in combination with insulin in patients with type 2 diabetes and severe renal impairment
}

This article was published in the following Dove Press journal:

Vascular Health and Risk Management

23 January 2013

Number of times this article has been viewed

\author{
Valentina Lukashevich' \\ Anja Schweizer ${ }^{2}$ \\ James E Foley' \\ Sheila Dickinson ${ }^{2}$ \\ Per-Henrik Groop ${ }^{3}$ \\ Wolfgang Kothny' \\ 'Novartis Pharmaceuticals \\ Corporation, East Hanover, NJ, \\ USA; ${ }^{2}$ Novartis Pharma AG, Basel, \\ Switzerland; ${ }^{3}$ Division of Nephrology, \\ Department of Medicine, Helsinki \\ University Central Hospital, \\ Folkhälsan Institute of Genetics, \\ Folkhälsan Research Center, \\ Biomedicum Helsinki, Finland, \\ and Baker IDI Heart and Diabetes \\ Institute, Melbourne, Victoria, \\ Australia
}

Correspondence: Valentina Lukashevich Novartis Pharmaceuticals Corporation, One Health Plaza, East Hanover, NJ 07936-1080, USA

Tel + I 862778245 I

Fax + I 973 78| 237|

Email valentina.lukashevich@novartis.com
Background: The purpose of this study was to evaluate the efficacy of vildagliptin $50 \mathrm{mg}$ once daily in patients with severe renal impairment (estimated glomerular filtration rate $<30 \mathrm{~mL} / \mathrm{min} / 1.73 \mathrm{~m}^{2}$ ) and longstanding type 2 diabetes not adequately controlled with insulin therapy, which is a difficult-to-treat population, with limited therapeutic options and a high susceptibility to hypoglycemia.

Methods: This was a post hoc subanalysis of data obtained during a previously described randomized, double-blind, parallel-group, 24-week study comparing the efficacy and safety of vildagliptin $50 \mathrm{mg}$ once daily versus placebo in patients with type 2 diabetes and moderate or severe renal impairment. The present data derive from 178 patients with severe renal impairment (baseline estimated glomerular filtration rate approximately $21 \mathrm{~mL} / \mathrm{min} / 1.73 \mathrm{~m}^{2}, 100$ randomized to vildagliptin, 78 randomized to placebo), all of whom were receiving insulin therapy (alone or in combination with an oral antidiabetic agent) for longstanding type 2 diabetes (mean approximately 19 years).

Results: With vildagliptin in combination with insulin, the adjusted mean change (AM $\Delta$ ) in $\mathrm{HbA}_{1 \mathrm{c}}$ from baseline $(7.7 \% \pm 0.1 \%)$ was $-0.9 \% \pm 0.4 \%$ and the between-treatment difference (vildagliptin - placebo) was $-0.6 \% \pm 0.2 \%(P<0.001)$. The percentage of patients achieving endpoint $\mathrm{HbA}_{1 \mathrm{c}}<7.0 \%$ was significantly higher with vildagliptin than placebo $(45.2 \%$ versus $22.8 \%, P=0.008$ ). When added to insulin, vildagliptin and placebo had comparable hypoglycemic profiles and did not cause weight gain. Both treatments were similarly well tolerated, with comparable incidences of adverse events, serious adverse events, and deaths.

Conclusion: When added to insulin therapy in patients with severe renal impairment and longstanding type 2 diabetes, vildagliptin $50 \mathrm{mg}$ once daily was efficacious, eliciting $\mathrm{HbA}_{1 \mathrm{c}}$ reductions consistent with those previously reported for a patient population with much more recent onset of type 2 diabetes and normal renal function, and had a hypoglycemic profile comparable with placebo. Accordingly, vildagliptin is a suitable treatment option for patients with advanced type 2 diabetes and impaired renal function who require insulin therapy and present a serious therapeutic challenge in clinical practice.

Keywords: chronic kidney disease, antidiabetic drug, dipeptidyl peptidase-4 inhibitor, glucagon-like peptide-1, type 2 diabetes

\section{Introduction}

Chronic kidney disease is a common complication in patients with diabetes, ${ }^{1}$ and hyperglycemia in patients with renal impairment is difficult to manage due to the limited therapeutic options and high prevalence of comorbidities. ${ }^{2-4}$ Longstanding type 2 diabetes in patients with advanced kidney disease often requires insulin therapy. ${ }^{5,6}$ Insulin dosage is a real challenge in a renally impaired population due to impaired 
catabolism and clearance of insulin. The renal clearance of insulin shows little change if the glomerular filtration rate (GFR) is above $40 \mathrm{~mL} / \mathrm{min}$, but it falls precipitously with further progression of chronic kidney disease, especially when

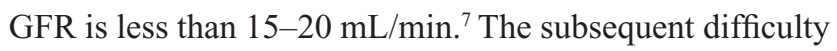
with insulin dose selection increases the risk of hypoglycemia, which is already a limiting factor in the maintenance of good glycemic control in patients receiving insulin ${ }^{8}$ and is further exacerbated by renal impairment. ${ }^{9,10}$ Thus, patients with severe renal impairment and type 2 diabetes inadequately controlled with insulin comprise a growing population with an unmet medical need for new therapies that lower blood glucose without increasing the risk of hypoglycemia. ${ }^{11}$

Vildagliptin is a dipeptidyl peptidase-4 inhibitor that blocks the inactivation of glucagon-like peptide-1 and glucose-dependent insulinotropic polypeptide, thus raising plasma concentrations of the intact, active form of these peptides and thereby improving islet function by increasing $\alpha$-cell and $\beta$-cell sensitivity to glucose. ${ }^{12,13}$ In patients with type 2 diabetes and normal renal function (or mild renal impairment) vildagliptin is effective as monotherapy ${ }^{14-18}$ and in combination with a variety of antidiabetic drugs. ${ }^{19-25}$ In all of these studies, vildagliptin has consistently evinced a low hypoglycemic potential, including in patients with advanced type 2 diabetes who required insulin therapy.

The efficacy and safety of vildagliptin $50 \mathrm{mg}$ once daily was also recently demonstrated in patients with moderate or severe renal impairment both after 24 weeks ${ }^{26}$ and one year of treatment. ${ }^{27}$ In the aforementioned study, ${ }^{26}$ $80 \%$ of patients with severe renal impairment (estimated GFR $<30 \mathrm{~mL} / \mathrm{min} / 1.73 \mathrm{~m}^{2}$ ) had inadequate glycemic control while receiving insulin therapy at baseline, reflecting the limited therapeutic options in this population, and providing a unique opportunity to examine the question of whether vildagliptin in combination with insulin was also efficacious, with a low hypoglycemic potential in patients with severe renal impairment, as it is in patients with less advanced type 2 diabetes and normal renal function. Accordingly, the present analysis was performed to assess the effects of vildagliptin in the subgroup of patients with advanced type 2 diabetes and severe renal impairment whose hyperglycemia was not adequately controlled with insulin alone or in combination with an oral antidiabetic agent at baseline.

\section{Materials and methods}

This is a post hoc subanalysis of data from a previously described randomized, double-blind, parallel-group, placebo-controlled, 24-week clinical trial assessing the efficacy and safety of vildagliptin $50 \mathrm{mg}$ once daily in patients with type 2 diabetes and moderate $(n=294)$ or severe $(n=221)$ renal impairment. The key entry criteria for the aforementioned trial included age $18-85$ years, $\mathrm{HbA}_{1 \mathrm{c}}$ $6.5 \%-10 \%$, and body mass index $18-42 \mathrm{~kg} / \mathrm{m}^{2}$. After a 2-week single-blind, placebo run-in period, eligible patients were randomized (week 0 , baseline) to vildagliptin $50 \mathrm{mg}$ once daily or placebo, and study visits occurred at 4-week intervals from week 4 to week 24 . The detailed methodology of this study has been described previously. ${ }^{26}$

The present data analysis includes only patients with severe renal impairment (estimated GFR by the Modification of Diet in Renal Disease formula $<30 \mathrm{~mL} / \mathrm{min} / 1.73 \mathrm{~m}^{2}$ ). Further, inclusion in this analysis required that patients were receiving ongoing insulin therapy, either alone, or in combination with an oral antidiabetic agent (ie, a sulfonylurea, meglitinide, or a thiazolidinedione), resulting in 178 patients contributing to the subanalysis.

Baseline insulin dose regimens were recorded, as were all major changes in insulin therapy (ie, increases or decreases in dose of $>20 \%$ of the baseline dose, or change of insulin type or addition of another insulin type). The mean insulin doses at baseline and endpoint were calculated from these records. Intensification of insulin therapy by increasing insulin dose $>20 \%$ or adding a new type(s) of insulin was defined as initiating rescue medication.

\section{Study assessments}

$\mathrm{HbA}_{1 \mathrm{c}}$ and fasting plasma glucose were assessed at all study visits. Responder analysis was also performed as described below. Hypoglycemia was defined as symptoms suggestive of low blood glucose confirmed by self-monitored blood glucose measurement $<3.1 \mathrm{mmol} / \mathrm{L}$ plasma glucose equivalent. Severe hypoglycemia was defined as any episode requiring assistance of another party (whether or not a confirmatory self-monitored blood glucose measurement was available). All adverse events were recorded and assessed by the investigator for severity and possible relationship to study medication.

\section{Statistical analysis}

The adjusted mean changes ( $\mathrm{AM} \Delta$ ) in $\mathrm{HbA}_{1 \mathrm{c}}$ and fasting plasma glucose from baseline to rescue-censored endpoint (with final observation carried forward for data censored at initiation of rescue medication) were compared between treatments using an analysis of covariance model with baseline value as covariate and background therapy, pooled center, and treatment as factors. A similar model (without 
background therapy as a factor) was used to determine $\mathrm{AM} \Delta \mathrm{HbA}_{1 \mathrm{c}}$ for patients with baseline $\mathrm{HbA}_{1 \mathrm{c}}>8.0 \%$ and baseline $\mathrm{HbA}_{1 \mathrm{c}}>9.0 \%$. Responder rates (percentage of patients with baseline $\mathrm{HbA}_{\mathrm{lc}} \geq 7.0 \%$ achieving endpoint $\mathrm{HbA}_{1 \mathrm{c}}<7.0 \%$ ) were assessed by treatment and compared by Chi-square test. Body weight, hypoglycemia, and safety data were summarized descriptively by treatment. Body weight and safety analyses were performed on all data collected, regardless of rescue medication use.

\section{Results}

Of the 221 patients with severe renal impairment randomized in the trial, 178 patients (100 in the vildagliptin group and 78 in the placebo group) were receiving insulin treatment at baseline. Table 1 summarizes the baseline demographic and background characteristics in the randomized population. These insulin-treated patients with severe renal impairment had a mean age of 64 years (with over half of the participants $\geq 65$ years of age), mean $\mathrm{HbA}_{1 \mathrm{c}}$ of $7.7 \%$, mean

Table I Patient baseline demographic and background characteristics by treatment (randomized population)

\begin{tabular}{|c|c|c|}
\hline Mean \pm SD or $n(\%)$ & $\begin{array}{l}\text { Vildagliptin } \\
50 \mathrm{mg} \text { once } \\
\text { daily }(\mathrm{n}=100)\end{array}$ & $\begin{array}{l}\text { Placebo } \\
(n=78)\end{array}$ \\
\hline \multicolumn{3}{|c|}{ Demographic variable or background characteristic* } \\
\hline Mean age (years) & $64.1 \pm 9.0$ & $64.9 \pm 11.3$ \\
\hline Age group $\geq 65$ years & $53(53.0)$ & $41(52.6)$ \\
\hline Gender, male & $5 I(51.0)$ & $4 I(52.6)$ \\
\hline \multicolumn{3}{|l|}{ Race } \\
\hline European & $49(49.0)$ & $40(51.3)$ \\
\hline Hispanic or Latino & $31(31.0)$ & $21(26.9)$ \\
\hline Asian & $17(17.0)$ & $16(20.5)$ \\
\hline Other & $3(3.0)$ & $\mathrm{I}(\mathrm{I} .3)$ \\
\hline Mean eGFR $\left(\mathrm{mL} / \mathrm{min} / \mathrm{l} .73 \mathrm{~m}^{2}\right)$ & $21.7 \pm 5.6$ & $20.6 \pm 6.7$ \\
\hline Mean BMI $\left(\mathrm{kg} / \mathrm{m}^{2}\right)$ & $30.8 \pm 5.8$ & $29.6 \pm 5.0$ \\
\hline $\mathrm{BMI} \geq 30 \mathrm{~kg} / \mathrm{m}^{2}$ & $53(53.0)$ & $35(44.9)$ \\
\hline Mean $\mathrm{HbA}_{\mathrm{Ic}}(\%)$ & $7.7 \pm 1.0$ & $7.7 \pm 1.1$ \\
\hline $\mathrm{HbA}_{\mathrm{Ic}}>8.0 \% ; \mathrm{n}(\%)$ & $30(30.0)$ & $29(37.2)$ \\
\hline $\mathrm{HbA}_{\mathrm{Ic}}>9.0 \% ; \mathrm{n}(\%)$ & $15(15.0)$ & II (I4.I) \\
\hline Mean FPG (mmol/L) & $8.1 \pm 2.8$ & $8.5 \pm 3.5$ \\
\hline Mean duration of T2DM (years) & $18.8 \pm 8.3$ & $20.2 \pm 9.5$ \\
\hline \multicolumn{3}{|l|}{ Antidiabetic therapy at BL, n (\%) } \\
\hline Insulin monotherapy & $87(87.0)$ & $66(84.6)$ \\
\hline Insulin + OAD(s) & $13(13.0)$ & $12(15.4)$ \\
\hline Insulin + SU & II (II.0) & $5(6.4)$ \\
\hline Mean insulin dose at baseline ( $\mathrm{U} /$ day) & $53.1 \pm 35.9$ & $49.6 \pm 41.6$ \\
\hline Mean duration of insulin use (years) & $5.3 \pm 5.9$ & $5.2 \pm 6.4$ \\
\hline
\end{tabular}

Note: *There were no significant between-group differences in any baseline characteristic.

Abbreviations: BL, baseline; BMI, body mass index; GFR, glomerular filtration rate; $\mathrm{HbA}_{\mathrm{Ic}}$, glycosylated hemoglobin; T2DM, type 2 diabetes mellitus; OAD, oral antidiabetic agent; SD, standard deviation; SU, sulfonylurea; FPG, fasting plasma glucose. estimated GFR of approximately $21 \mathrm{~mL} / \mathrm{min} / 1.73 \mathrm{~m}^{2}$ and mean body mass index of $30 \mathrm{~kg} / \mathrm{m}^{2}$. They had longstanding type 2 diabetes (mean duration of known type 2 diabetes was about 19 years), with a mean duration of insulin use of about 5 years. The majority of patients were receiving basal insulin at baseline, alone or in a basal/bolus regimen. The mean insulin dose at baseline was approximately $53 \mathrm{U} /$ day in patients randomized to vildagliptin and about $50 \mathrm{U} /$ day in those randomized to placebo, and did not change meaningfully in either group during the study. Fewer than $15 \%$ of patients were receiving an oral antidiabetic agent in addition to insulin, primarily sulfonylureas. The treatment groups were generally well balanced with respect to baseline characteristics.

Figure 1 depicts the time course of mean $\mathrm{HbA}_{1 \mathrm{c}}$ during 24 weeks of treatment with vildagliptin $50 \mathrm{mg}$ once daily or placebo added to prior insulin therapy. $\mathrm{HbA}_{1 \mathrm{c}}$ values were consistently lower in the vildagliptin compared with the placebo group at all post-baseline visits. In the vildagliptin group, the $\mathrm{AM} \Delta \mathrm{HbA}_{1 \mathrm{c}}$ from baseline $(7.7 \% \pm 0.1 \%)$ to endpoint was $-0.9 \% \pm 0.4 \%$, while in the placebo group baseline $\mathrm{HbA}_{1 \mathrm{c}}$ averaged $7.8 \% \pm 0.1 \%$ and the $\mathrm{AM} \Delta$ was $-0.3 \% \pm 0.4 \%$. The between-treatment difference in $\mathrm{AM} \Delta \mathrm{HbA}_{1 \mathrm{c}}$ (vildagliptin - placebo) was $-0.6 \% \pm 0.2 \%$ $(P<0.001)$.

The percentage of patients (with baseline $\mathrm{HbA}_{1 \mathrm{c}} \geq 7.0 \%$ ) achieving endpoint $\mathrm{HbA}_{1 \mathrm{c}}<7.0 \%$ in the vildagliptin group (33/73 patients, $45.2 \%)$ was twice that in the placebo group (13/57 patients, $22.8 \%, P=0.008)$. Further, in patients with high baseline $\mathrm{HbA}_{1 \mathrm{c}}>8.0 \%$, the absolute reduction in $\mathrm{HbA}_{1 \mathrm{c}}$ with vildagliptin (baseline $9.0 \%, \mathrm{AM} \Delta-1.4 \% \pm 0.3 \%, \mathrm{n}=30$ ) was greater than in the overall study population, while there was a minor decrease with placebo (baseline 8.9\%, $\mathrm{AM} \Delta-0.2 \% \pm 0.3 \%, \mathrm{n}=29)$, resulting in a between-group difference in $\mathrm{AM} \Delta$ (vildagliptin - placebo) of $-1.1 \% \pm 0.3 \%$ $(P=0.001)$. In patients with baseline $\mathrm{HbA}_{1 \mathrm{c}}>9.0 \%$, the decrease in $\mathrm{HbA}_{1 \mathrm{c}}$ with vildagliptin was still larger (baseline $\left.\mathrm{HbA}_{1 \mathrm{c}} 9.5 \%, \mathrm{n}=15, \mathrm{AM} \Delta \mathrm{HbA}_{1 \mathrm{c}}-1.8 \% \pm 0.5 \%\right)$, as was the between-treatment difference $(-2.2 \% \pm 0.7 \%, P=0.008)$.

Fasting plasma glucose also decreased with vildagliptin plus insulin treatment. Baseline fasting plasma glucose averaged $8.1 \pm 0.3 \mathrm{mmol} / \mathrm{L}$ in the vildagliptin group, and the AM $\Delta$ fasting plasma glucose was $-2.4 \pm 1.1 \mathrm{mmol} / \mathrm{L}$. The between-treatment difference was $-0.8 \pm 0.4 \mathrm{mmol} / \mathrm{L}$; however, this did not achieve statistical significance $(P=0.063)$.

The hypoglycemia profile was generally similar between vildagliptin and placebo when added to insulin. In the 


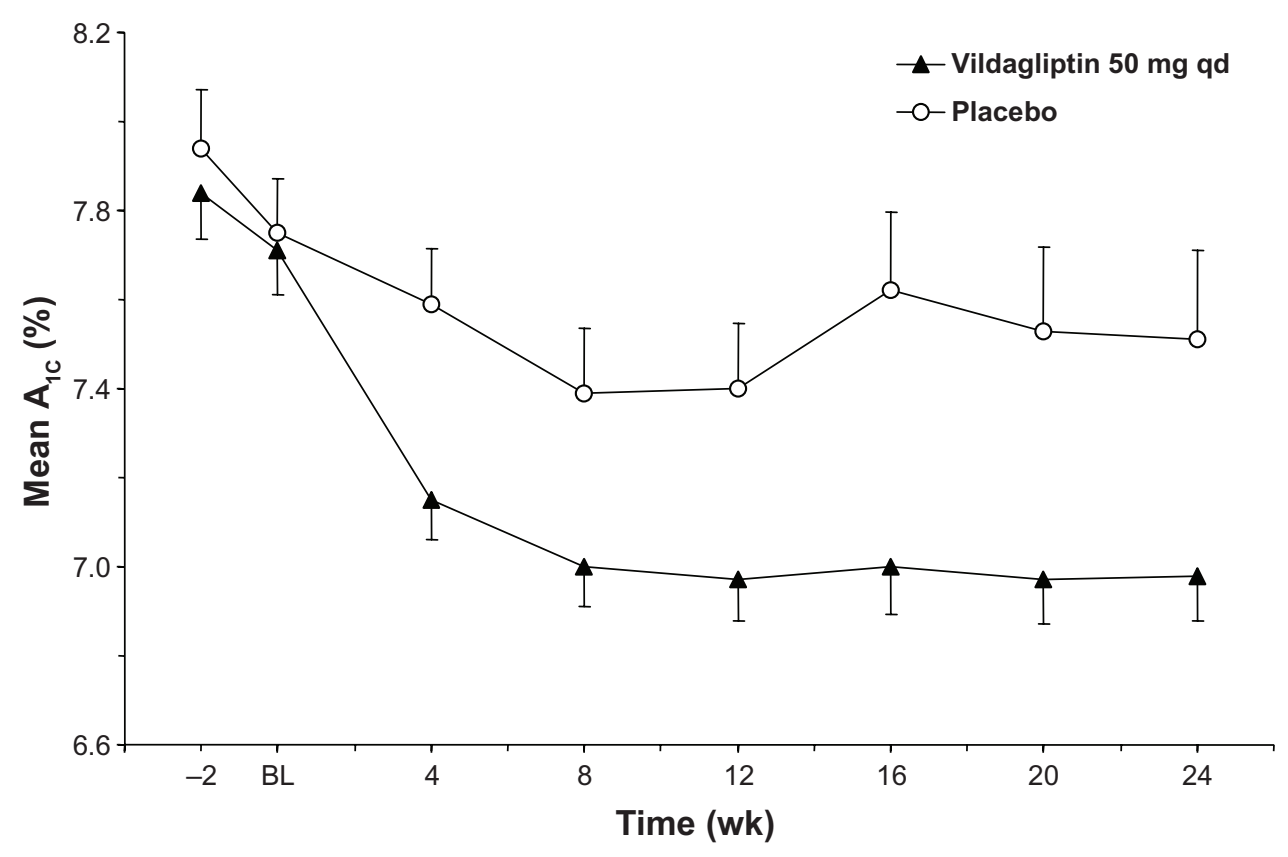

Figure I Time course of mean $\mathrm{HbA}_{\mathrm{Ic}}$ in patients with severe renal impairment receiving insulin therapy.

Notes: Mean \pm standard error. $n$ for vildagliptin group at baseline and week $24=99$ and 81 patients, respectively; $n$ for placebo group at baseline and week $24=77$ and 59 , respectively.

vildagliptin group, 19/100 patients (19.0\%) experienced a total of 36 hypoglycemic events. In the placebo group, $11 / 78$ patients ( $14.1 \%$ ) experienced a total of 36 hypoglycemic events. Thus, in the placebo group, of the patients reporting any hypoglycemic event, a higher percentage reported two or more events $(72.7 \%$ with placebo versus $47.4 \%$ with vildagliptin). Severe hypoglycemia was reported at a similarly low rate in the two groups $(2.0 \%$ with vildagliptin and $2.6 \%$ with placebo).

Body weight remained constant in the vildagliptin group; baseline body weight averaged $82.2 \pm 1.9 \mathrm{~kg}$ and the mean body weight at week 24 was $82.1 \pm 2.2 \mathrm{~kg}$. In the placebo group, baseline body weight was $78.7 \pm 1.7 \mathrm{~kg}$ and at week 24 body weight averaged $79.4 \pm 1.9 \mathrm{~kg}$.

The overall adverse event profile was also similar in the two treatment groups, and there were no notable differences in the subgroup of insulin-treated patients with severe renal impairment compared with the overall study population that was previously reported. The percentage of patients receiving vildagliptin in combination with insulin and experiencing one or more adverse event, severe adverse event, or adverse event leading to discontinuation were $79.0 \%, 19.0 \%$, and $10.0 \%$, respectively. The corresponding percentages for the placebo plus insulin group were $76.9 \%, 24.4 \%$ and $6.4 \%$, respectively. Apart from hypoglycemia, the most common specific adverse events were edema, hyperhidrosis, and dizziness. They were reported by similar percentages of patients in the vildagliptin and placebo groups. Two patients receiving vildagliptin $(2.0 \%)$ and four patients receiving placebo (5.1\%) died during the study: none of the deaths were suspected to be related to study medication.

There was no deterioration of renal function in either group after 24 weeks of treatment. The mean estimated GFRs at baseline were $21.8 \pm 0.5$ and $20.7 \pm 0.8 \mathrm{~mL} / \mathrm{min} / 1.73 \mathrm{~m}^{2}$ in the vildagliptin and placebo group, respectively, and were $20.9 \pm 0.7$ and $19.3 \pm 1.1 \mathrm{~mL} / \mathrm{min} / 1.73 \mathrm{~m}^{2}$ at week 24 .

\section{Discussion}

As mentioned in detail previously, patients with severe renal impairment and advanced type 2 diabetes requiring insulin therapy comprise a difficult-to-treat patient population with a high propensity for hypoglycemia. The main findings of the present subanalysis of data from such a population were that vildagliptin added to insulin markedly improved glycemic control and had a hypoglycemic profile similar to placebo.

The magnitude of the glucose-lowering seen in this subgroup $\left(\mathrm{HbA}_{1 \mathrm{c}}\right.$ reduction $0.9 \%$ from baseline of $7.7 \%$ ) was in the range seen previously in studies of vildagliptin monotherapy and combination therapy in patients with a much shorter history of type 2 diabetes and normal renal function. ${ }^{19,28,29}$ Relative to placebo added to insulin, the decrease in $\mathrm{HbA}_{1 \mathrm{c}}$ with vildagliptin added to insulin $(-0.6 \%)$ was clinically meaningful. As expected, the magnitude of reduction in $\mathrm{HbA}_{1 \mathrm{c}}$ and the between-treatment difference was larger in patients 
with higher baseline $\mathrm{HbA}_{1 \mathrm{c}}$ levels. Thus, the $\beta$-cell dysfunction and other metabolic derangements attendant with severe renal impairment ${ }^{2}$ and longstanding type 2 diabetes requiring insulin therapy ${ }^{10}$ clearly did not mitigate the efficacy or the low hypoglycemic potential of vildagliptin.

The fasting plasma glucose decreased modestly and the $\mathrm{AM} \Delta$ fasting plasma glucose was not significantly different from placebo. This likely reflects the fact that the majority of patients were receiving basal insulin prior to intervention, and this form of therapy itself reduces the contribution of fasting plasma glucose to overall glycemic exposure (as reflected by $\left.\mathrm{HbA}_{1 \mathrm{c}}\right) .{ }^{30}$

Generally, an improvement in glycemic control in the range found in the present analysis, with nearly half of the patients achieving target $\mathrm{HbA}_{1 \mathrm{c}}<7 \%$, is expected to be associated with a marked increase in hypoglycemia, particularly in patients with longstanding disease requiring insulin. ${ }^{31-33}$ Therefore, the finding that there was no overall increase in hypoglycemia with vildagliptin despite a clinically meaningful decrease in $\mathrm{HbA}_{1 \mathrm{c}}$ is notable. While there was a slight increase in the number of patients experiencing hypoglycemic events with vildagliptin added to insulin $(19.0 \%$ versus $14.1 \%$ with placebo), the number of hypoglycemic episodes was identical with vildagliptin (36 episodes/100 patients) and placebo (36 episodes/78 patients), and there was a similarly low risk of severe hypoglycemia ( $2.0 \%$ with vildagliptin versus $2.6 \%$ with placebo). Thus, the question arises of how such glucose-lowering occurs without increased hypoglycemia, as shown in the present analysis with vildagliptin added to insulin. A possible explanation is that vildagliptin enhances the counter-regulatory response to incipient hypoglycemia, which is greatly impaired in insulin-dependent patients with type 2 diabetes, who have more progressive damage of pancreatic islets compared with patients with less advanced type 2 diabetes and treated with oral antidiabetic agents. ${ }^{10}$

An effect of vildagliptin on glucagon counter-regulation during hypoglycemia in drug-naïve patients with type 2 diabetes was indeed demonstrated in a mechanistic study examining the glucagon response to hypoglycemia in patients with type 2 diabetes using stepped hypoglycemic clamps. ${ }^{13}$ In that study, the increase in glucagon that occurred during the hypoglycemic clamp step at $2.5 \mathrm{mmol} / \mathrm{L}$ was significantly greater in vildagliptin-treated patients than in placebo-treated patients, representing a $38 \%$ increase with vildagliptin. This is likely due to the glucose-dependent nature of the effects of glucagon-like peptide- 1 and glucose-dependent insulinotropic polypeptide on insulin ${ }^{34,35}$ and glucagon ${ }^{36-38}$ secretion, through which vildagliptin acts.
In addition to the present subanalysis of vildagliptin added to insulin in patients with severe renal impairment, there are two previous clinical studies of vildagliptin added to insulin in patients with normal renal function or mild renal impairment. In the first such study, by Fonseca et $\mathrm{al}^{24}$ in patients on high doses of insulin ( $>80 \mathrm{U} /$ day) and multiple injections of short-acting insulin(s), addition of vildagliptin significantly decreased both the frequency and severity of hypoglycemia relative to placebo plus insulin, while producing a modest improvement in glycemic control $(-0.3 \%$ relative to placebo). In a recent 24 -week, placebocontrolled study by Kothny et al, ${ }^{25}$ vildagliptin added to basal or premixed insulin (about $40 \mathrm{U} /$ day) with or without metformin elicited a marked improvement in glycemic control $(-0.7 \%$ relative to placebo), with no increase in the incidence of hypoglycemia compared with placebo added to insulin ( $8.4 \%$ versus $7.2 \%$, respectively). The reduction in incidence of hypoglycemia in the earlier study ${ }^{24}$ could be potentially explained by the improved counter-regulation with vildagliptin, which not only prevents hypoglycemia when the glucose level drops, but also can reduce hypoglycemia when the underlying incidence and severity of this complication is already high. A higher underlying incidence of hypoglycemia and more modest glucose-lowering effect seen in the earlier study compared with the study by Kothny et al and our present analysis are likely due to differences in the insulin regimens utilized in these studies, which reflect the changes in the treatment paradigm of insulin therapy in type 2 diabetes towards predominant use of basal insulin (with or without metformin $)^{39}$ versus short-acting insulin in the past.

An alternative to adding vildagliptin to ongoing insulin therapy in patients with severe renal impairment and type 2 diabetes could be simply to increase the dose of insulin employed, or add another type of insulin to the regimen. However, it is well known that hypoglycemia is the limiting factor in managing diabetes with insulin, ${ }^{40,41}$ especially in patients with renal impairment who actually require a reduction of the insulin dose with the progression of renal impairment. ${ }^{10}$ Accordingly, it may be assumed that increasing the insulin dose would substantially increase the frequency of hypoglycemia. The present study was designed to assess the efficacy of vildagliptin added to stable, existing type 2 diabetes therapy in patients with renal impairment, and therefore cannot address how vildagliptin would compare with insulin intensification. Nonetheless, a confirmative noninferiority study where vildagliptin is compared with intensification of insulin treatment could be an important follow-up to the current work. 
The general safety and tolerability of vildagliptin in patients with severe renal impairment was addressed in detail previously ${ }^{26,27}$ and, not surprisingly, no new safety signals were identified in the present subanalysis.

In conclusion, the present substudy confirms that vildagliptin is a suitable therapeutic option for patients with declining renal function and advanced type 2 diabetes who require insulin treatment. When added to insulin therapy in patients with severe renal impairment and longstanding type 2 diabetes, vildagliptin $50 \mathrm{mg}$ once daily was efficacious and well tolerated, without increasing the risk or severity of hypoglycemic episodes, without weight gain, and with $\mathrm{HbA}_{1 \mathrm{c}}$ reductions consistent with those previously reported in patients with much more recent onset of type 2 diabetes and normal renal function.

\section{Acknowledgments}

The authors gratefully acknowledge the investigators and staff at the 108 participating centers. A list of principal investigators is provided in the Appendix. Editorial assistance was provided by Beth Dunning Lower. This work was funded by Novartis Pharmaceuticals Corporation.

\section{Disclosure}

P-HG has served on advisory boards for Novartis, Boehringer Ingelheim, and Cebix, has received honoraria for speaking engagements from Novartis, Boehringer Ingelheim, Novo-Nordisk, Eli Lilly, Genzyme, and MSD Finland, and has received research support from Eli Lilly. JEF, AS, SD, and WK are employed by and own shares in Novartis. VL is employed by Novartis.

\section{References}

1. Middleton RJ, Foley RN, Hegarty J, et al. The unrecognized prevalence of chronic kidney disease in diabetes. Nephrol Dial Transplant. 2006;21: 88-92.

2. DeFronzo RA, Tobin JD, Rowe JW, Andres R. Glucose intolerance in uremia. Quantification of pancreatic beta cell sensitivity to glucose and tissue sensitivity to insulin. J Clin Invest. 1978;62:425-435.

3. Scott $\mathrm{D}$, Davidson JA. Managing chronic kidney disease in type 2 diabetes in family practice. J Natl Med Assoc. 2011;103:952-959.

4. Targher G, Chonchol M, Pichiri I, Zoppini G. Risk of cardiovascular disease and chronic kidney disease in diabetic patients with non-alcoholic fatty liver disease: just a coincidence? J Endocrinol Invest. 2011;34:544-551.

5. Koro CE, Lee BH, Bowlin SJ. Antidiabetic medication use and prevalence of chronic kidney disease among patients with type 2 diabetes mellitus in the United States. Clin Ther. 2009;31:2608-2617.

6. Snyder RW, Berns JS. Use of insulin and oral hypoglycemic medications in patients with diabetes mellitus and advanced kidney disease. Semin Dial. 2004;17:365-370.

7. Mak RH. Impact of end-stage renal disease and dialysis on glycemic control. Semin Dial. 2000;13:4-8.

8. Cryer PE. Hypoglycaemia: the limiting factor in the glycaemic management of type I and type II diabetes. Diabetologia. 2002;45:937-948.
9. Arem R. Hypoglycemia associated with renal failure. Endocrinol Metab Clin North Am. 1989;18:103-121.

10. Ferrannini E, Groop PH, Nauck M, Fioretto P, Hach T, Thomas M. The Significance of the Kidney in Diabetes. Konigswinter, Germany: infill Kommunikation $\mathrm{GmbH} ; 2012$.

11. Abe M, Okada K, Soma M. Antidiabetic agents in patients with chronic kidney disease and end-stage renal disease on dialysis: metabolism and clinical practice. Curr Drug Metab. 2011;12:57-69.

12. Ahren B, Schweizer A, Dejager S, Villhauer EB, Dunning BE, Foley JE. Mechanisms of action of the DPP-4 inhibitor vildagliptin in man. Diabetes Obes Metab. 2011;13:775-783.

13. Ahren B, Schweizer A, Dejager S, et al. Vildagliptin enhances islet responsiveness to both hyper- and hypoglycemia in patients with type 2 diabetes. J Clin Endocrinol Metab. 2009;94:1236-1243.

14. Dejager S, Schweizer A, Foley JE. Evidence to support the use of vildagliptin monotherapy in the treatment of type 2 diabetes mellitus. Vasc Health Risk Manag. 2012;8:339-348.

15. Dejager S, Razac S, Foley JE, Schweizer A. Vildagliptin in drug-naive patients with type 2 diabetes: a 24-week, double-blind, randomized, placebo-controlled, multiple-dose study. Horm Metab Res. 2007;39: 218-223.

16. Goke B, Hershon K, Kerr D, et al. Efficacy and safety of vildagliptin monotherapy during 2-year treatment of drug-naive patients with type 2 diabetes: comparison with metformin. Horm Metab Res. 2008;40: 892-895.

17. Pi-Sunyer FX, Schweizer A, Mills D, Dejager S. Efficacy and tolerability of vildagliptin monotherapy in drug-naive patients with type 2 diabetes. Diabetes Res Clin Pract. 2007;76:132-138.

18. Schweizer A, Couturier A, Foley JE, Dejager S. Comparison between vildagliptin and metformin to sustain reductions in $\mathrm{HbA}_{1 \mathrm{c}}$ over one year in drug-naïve patients with type 2 diabetes. Diabet Med. 2007;24: 955-961.

19. Bosi E, Camisasca RP, Collober C, Rochotte E, Garber AJ. Effects of vildagliptin on glucose control over 24 weeks in patients with type 2 diabetes inadequately controlled with metformin. Diabetes Care. 2007;30:890-895.

20. Rosenstock J, Baron MA, Camisasca RP, Cressier F, Couturier A, Dejager S. Efficacy and tolerability of initial combination therapy with vildagliptin and pioglitazone compared with component monotherapy in patients with type 2 diabetes. Diabetes Obes Metab. 2007;9: 175-185.

21. Garber AJ, Foley JE, Banerji MA, et al. Effects of vildagliptin on glucose control in patients with type 2 diabetes inadequately controlled with a sulphonylurea. Diabetes Obes Metab. 2008;10:1047-1056.

22. Garber AJ, Schweizer A, Baron MA, Rochotte E, Dejager S. Vildagliptin in combination with pioglitazone improves glycaemic control in patients with type 2 diabetes failing thiazolidinedione monotherapy: a randomized, placebo-controlled study. Diabetes Obes Metab. 2007;9: $166-174$.

23. Bolli G, Dotta F, Rochotte E, Cohen SE. Efficacy and tolerability of vildagliptin versus. pioglitazone when added to metformin: a 24-week, randomized, double-blind study. Diabetes Obes Metab. 2008;10:82-90.

24. Fonseca V, Schweizer A, Albrecht D, Baron MA, Chang I, Dejager S. Addition of vildagliptin to insulin improves glycaemic control in type 2 diabetes. Diabetologia. 2007;50:1148-1155.

25. Kothny W, Foley J, Kozlovski P, Shao Q, Gallwitz B, Lukashevich V. Improved glycemic control with vildagliptin added to insulin, with or without metformin, in patients with type 2 diabetes mellitus. Diab Obes Metab. October 5, 2012. [Epub ahead of print.]

26. Lukashevich V, Schweizer A, Shao Q, Groop PH, Kothny W. Safety and efficacy of vildagliptin versus placebo in patients with type 2 diabetes and moderate or severe renal impairment: a prospective 24-week randomized placebo-controlled trial. Diabetes Obes Metab. 2011;13:947-954.

27. Kothny W, Shao Q, Groop PH, Lukashevich V. One-year safety, tolerability and efficacy of vildagliptin in patients with type 2 diabetes and moderate or severe renal impairment. Diabetes Obes Metab. 2012;14:1032-1039. 
28. Ahren B, Gomis R, Standl E, Mills D, Schweizer A. Twelve- and 52-week efficacy of the dipeptidyl peptidase IV inhibitor LAF237 in metformin-treated patients with type 2 diabetes. Diabetes Care. 2004;27:2874-2880.

29. Schweizer A, Dejager S, Bosi E. Comparison of vildagliptin and metformin monotherapy in elderly patients with type 2 diabetes: a 24-week, double-blind, randomized trial. Diabetes Obes Metab. 2009;11:804-812.

30. Riddle M, Umpierrez G, DiGenio A, Zhou R, Rosenstock J. Contributions of basal and postprandial hyperglycemia over a wide range of $\mathrm{A} 1 \mathrm{C}$ levels before and after treatment intensification in type 2 diabetes. Diabetes Care. 2011;34:2508-2514.

31. Miller CD, Phillips LS, Ziemer DC, Gallina DL, Cook CB, El-Kebbi IM. Hypoglycemia in patients with type 2 diabetes mellitus. Arch Intern Med. 2001;161:1653-1659.

32. Amiel SA, Dixon T, Mann R, Jameson K. Hypoglycaemia in type 2 diabetes. Diabet Med. 2008;25:245-254.

33. Leese GP, Wang J, Broomhall J, et al. Frequency of severe hypoglycemia requiring emergency treatment in type 1 and type 2 diabetes: a population-based study of health service resource use. Diabetes Care. 2003;26:1176-1180.

34. Vilsboll T, Krarup T, Madsbad S, Holst JJ. Both GLP-1 and GIP are insulinotropic at basal and postprandial glucose levels and contribute nearly equally to the incretin effect of a meal in healthy subjects. Regul Pept. 2003;114:115-121.
35. Kreymann B, Williams G, Ghatei MA, Bloom SR. Glucagon-like peptide-1 7-36: a physiological incretin in man. Lancet. 1987;2: 1300-1304.

36. Nauck MA, Kleine N, Orskov C, Holst JJ, Willms B, Creutzfeldt W. Normalization of fasting hyperglycaemia by exogenous glucagon-like peptide 1 (7-36 amide) in type 2 (non-insulin-dependent) diabetic patients. Diabetologia. 1993;36:741-744.

37. Meier JJ, Gallwitz B, Siepmann N, et al. Gastric inhibitory polypeptide (GIP) dose-dependently stimulates glucagon secretion in healthy human subjects at euglycaemia. Diabetologia. 2003;46:798-801.

38. Dunning BE, Foley JE, Ahren B. Alpha cell function in health and disease: influence of glucagon-like peptide-1. Diabetologia. 2005;48: 1700-1713.

39. Inzucchi SE, Bergenstal RM, Buse JB, et al. Management of hyperglycaemia in type 2 diabetes: a patient-centered approach. Position statement of the American Diabetes Association (ADA) and the European Association for the Study of Diabetes (EASD). Diabetologia. 2012;55:1577-1596.

40. Cryer PE. Hypoglycemia is the limiting factor in the management of diabetes. Diabetes Metab Res Rev. 1999;15:42-46.

41. Cryer PE. Hypoglycemia: still the limiting factor in the glycemic management of diabetes. Endocr Pract. 2008;14:750-756. 


\section{Appendix}

\section{Investigators contributing data to this study}

Argentina: Drs Diego Aizemberg, Andres Alvarisqueta, Ines Bartolacci, Maria Isabel Klyver de Saleme, Silvia Lapertosa, Virginia E Visco. Australia: Drs Joey Kaye, Joseph Proietto, Richard Simpson, Glenn Ward. Canada: Drs Andre Belanger, Gottesman, Jean-Pierre Halle, Andrew W Steele, Vincent Woo. Costa Rica: Drs Sonia Cerdas, Chi H Chen, Mario O Speranza, Mary V Vinocour. Finland: Drs Juha Kiesila, Pauliina Pippola. France: Drs Robert Arnou, Pierre Bataille, Guillaume Charpentier, Jean-Pierre Fauvel, Alfred Penfornis, Philippe Zaoui. Germany: Drs Bruno Allolio, Stefan Bornstein, Klemens Budde, Stefan Feige, Stefan Fischer, Ulrich R Foelsch, Helga Frank, Helmut Geiger, ClausMichael Grimm, Kai M Hahn, Hermann Haller, Igor Harsch, Dirk Hennig, Anton Koehler, Stephan Maxeiner, Ludwig Merker, Sybille Merscher-Steenken, Frank Pistrosch, Joachim
Schrader, Hjalmar B Steinhauer, Eckard Wilbrandt, Bernhard R Winkelmann. Guatemala: Drs Sergio L Bran, Vicente Sanchez, Erick Turcios. India: Drs Hemanga Barman, JB Gupta, Sunil M Jain, Parag Shah, Mathew Thomas. Norway: Dr Bard Kulseng. Russia: Drs Irina Y Demidova, Vladimir A Dobronravov, Ludmila A Ivanova, Irina A Karpova, Zhanna D Kobalava, Natalia A Koziolova, Elena V Kuchenkova, Anatoly I Kuzin, Olga E Lantseversusa, Olga D Ostroumova, Galina K Reshedko, Natalia N Vesikova, Dmitriy N Volkov, Vladimir S Zadionchenko. Spain: Drs Inaki Arguelles, Carlos Calvo, Carmen De la Cuesta Mayor, Enrique Esmatjes, Nuria Freixenet, Luis Manzano, Alberto Martinez Catelao, Juan A Paniagua, Luis de Teresa Parreno, Manel Terns, Carles Trescoli. Sweden: Drs Katarina Berndtsson Blom, Ulla-Britt Ericsson, Ibe Lager, Mona Landin-Olsson, and Mrs Maria Svensson.
Vascular Health and Risk Management

\section{Publish your work in this journal}

Vascular Health and Risk Management is an international, peerreviewed journal of therapeutics and risk management, focusing on concise rapid reporting of clinical studies on the processes involved in the maintenance of vascular health; the monitoring, prevention and treatment of vascular disease and its sequelae; and the involvement of

\section{Dovepress}

metabolic disorders, particularly diabetes. This journal is indexed on PubMed Central and MedLine. The manuscript management system is completely online and includes a very quick and fair peer-review system, which is all easy to use. Visit http://www.dovepress.com/ testimonials.php to read real quotes from published authors. 